\title{
Cognitive dysfunction in multiple sclerosis: Assessment, imaging, and risk factors
}

\author{
Mitchell T. Wallin, MD, MPH; ${ }^{1-3 *}$ Jeffrey A. Wilken, PhD; ${ }^{1,3-4}$ Robert Kane, PhD $^{3-4}$ \\ ${ }^{1}$ Washington, DC, Department of Veterans Affairs (VA) Medical Center, Washington, DC; ${ }^{2}$ Department of Neurology, \\ Georgetown University, Washington, DC; ${ }^{3}$ VA Maryland Health Care System, Multiple Sclerosis Center of Excellence \\ East, Baltimore, MD; ${ }^{4}$ Department of Psychology, University of Maryland, College Park, MD
}

\begin{abstract}
Up to $70 \%$ of multiple sclerosis (MS) patients experience cognitive dysfunction during the course of their disease. The most often affected domains are attention, memory, and information processing speed. Sequelae of cognitive dysfunction include negative effects on activities of daily living, employment, and relationships. This article reviews cognitive dysfunction in MS and focuses specifically on assessment, imaging, and risk factors. A number of neuropsychological batteries have been developed specifically for assessing cognitive dysfunction in MS patients. Trade-offs in length, administrative support, and efficiency exist between the various batteries. Modern imaging techniques provide a clearer picture of MS-related damage to the central nervous system, which is the major cause of cognitive dysfunction. Additionally, candidate risk factors have been identified that may help predict which patients will develop cognitive dysfunction.
\end{abstract}

Key words: central nervous system, cognition, cognitive testing, epidemiology, imaging, MRI, multiple sclerosis, neuropsychology, outcome, risk factors.

\section{INTRODUCTION}

Neuropsychological research over the past two decades has provided definitive evidence that multiple sclerosis (MS) causes deterioration in cognitive function in 30 to 70 percent of MS patients [1]. The severity of cognitive dysfunction in MS varies, as does the pattern of deficits. The domains that are most often affected are attention, memory, and information processing speed. Visuospatial perception and executive functioning may also be impaired, but language and intellectual function are typically preserved. The cognitive deficits seen in MS implicate a subcortical pathology similar to the subcortical dementias associated with other chronic diseases [2]. Sequelae of cognitive dysfunction include negative effects on activities of daily living (ADL), employment, and relationships [3].

In a review of the literature, Wishart and Sharpe found significant individual differences in the cognitive presentation of MS [4]. The authors noted that physical symptoms of the disease are not highly correlated with

Abbreviations: $\mathrm{ADL}=$ activities of daily living, $\mathrm{ANAM}=$ Automated Neuropsychological Assessment Metrics, APOE = apolipoprotein $\mathrm{E}$ (gene), $\mathrm{A} / \mathrm{T}$ = adenine/thymine, $\mathrm{BRB}-\mathrm{N}=$ Brief Repeatable Battery of Neuropsychological Tests, CNS = central nervous system, COWAT $=$ Controlled Oral Word Association Test, EDSS = Expanded Disability Status Scale, MACFIMS = Minimal Assessment of Cognitive Function in Multiple Sclerosis, $\mathrm{MRI}=$ magnetic resonance imaging, $\mathrm{MS}=$ multiple sclerosis, MSCoE = MS Center of Excellence, PASAT = Paced Auditory Serial Addition Test, SDMT $=$ Symbol Digit Modalities Test, VA = Department of Veterans Affairs.

${ }^{*}$ Address all correspondence to Mitchell T. Wallin, MD, MPH; Neurology Service 127, VA Medical Center, 50 Irving Street NW, Washington, DC 20422; 202-745-8148; fax: 202-745-8231. Email: mitchell.wallin@med.va.gov

DOI: 10.1682/JRRD.2004.09.0120 
cognitive symptoms. For example, patients with numerous physical symptoms may not have significant cognitive symptoms. Conversely, patients with numerous MSrelated cognitive difficulties may have minimal physical symptoms. Evidence from one longitudinal study indicates that physical and cognitive function tend to converge if follow-up is long enough [5]. Nonetheless, physical disease does not appear to be the best predictor of cognitive dysfunction in MS. Although the variables that lead to cognitive dysfunction in MS are not well understood, advances in neuroimaging and genetic technology provide promising approaches to the discovery of new predictors.

In this article we review cognitive dysfunction in MS and focus on assessment, imaging, and risk factors. Factors that affect the development or progression of cognitive dysfunction will be discussed. Treatment for MS cognitive dysfunction is limited and we refer the reader to recent reports for more information [6-9]. Therapy options will not be discussed in this review.

\section{ASSESSMENT}

Like physical disability, cognitive dysfunction has major implications for ADL, employment, and independence. Because cognitive dysfunction is seen in approximately half of all MS patients [1,10-11], detection, characterization, and monitoring of its progression should be part of routine care. Assessment of comorbid disorders that may influence and even mimic cognitive dysfunction is also important. Among the most common comorbid disorders are depression and fatigue. Recent reports have shown that depression and fatigue are commonly seen with cognitive dysfunction [12-13] and may be the result of MS-related neuronal dysfunction [14]. Independently, either disorder can cause poor attention and psychomotor slowing. The Beck Depression Inventory [15] and the Fatigue Severity Scale [16] are commonly used for assessing depression and fatigue, respectively.

Since MS can affect various sites within the brain, no single cognitive deficit pattern is characteristic of all patients with MS. However, specific deficits tend to be seen in MS, especially earlier in the disease. These deficits include problems with memory, attention, executive functioning, generative fluency, and information processing speed $[1,10]$. This constellation of problems is frequently associated with subcortical lesions as opposed to the deficit patterns often associated with more diffuse cortical brain involvement [17]. Rarely, MS has been found to produce classic cortical deficits [18]. A model for the most commonly seen problems in MS will provide strategies for assessment.

The benchmark for specific assessment of cognitive function in MS patients has been the comprehensive neuropsychological assessment battery. Neuropsychological examinations can be conducted for detecting cognitive changes, monitoring treatment effects, characterizing deficits for rehabilitation planning, or documenting the range of patient impairment for guiding decisions regarding disability. Unfortunately, comprehensive neuropsychological testing can be expensive and rather lengthy. Thus, a main thrust of MS assessment work over the last several years has been the development of shorter batteries for screening. These batteries focus on cognitive dysfunction associated with subcortical disease.

In this article, we emphasize screening methods for detecting cognitive dysfunction associated with MS, identifying temporal trends, and monitoring functional status. The batteries highlighted in Table 1 reflect three of the main schools of thought regarding screening of MS patients for cognitive dysfunction:

1. Short screening with traditional measures in a neurologist's office.

2. Testing by a neuropsychologist with a minimal (but comprehensive) neurocognitive battery.

3. Testing with automated, computerized measures in a neurologist's office or as part of a clinical trial.

Rao et al. proposed a brief battery for assessing cognitive changes in MS [1]. This Brief Repeatable Battery of Neuropsychological Tests (BRB-N) was designed for use by nonneuropsychologists. Thus, it can be administered and scored in a neurologist's office. The BRB-N is composed of the Buschke Selective Reminding Test, the 7/24 Spatial Recall Test, the Paced Auditory Serial Addition Test (PASAT), and the Controlled Oral Word Association Test (COWAT). Other researchers have added the Symbol Digit Modalities Test (SDMT) to this battery. The battery can be administered in approximately 20 to 30 minutes depending on the patient and the exact composition of tests. At least one alternate form is available for most of the tests recommended by Rao [19]. Although the battery has specificity of 94 percent and sensitivity of 71 percent when used for detecting cognitive dysfunction in MS patients, test-retest reliability 
Table 1.

Three approaches to cognitive dysfunction screening in multiple sclerosis patients.

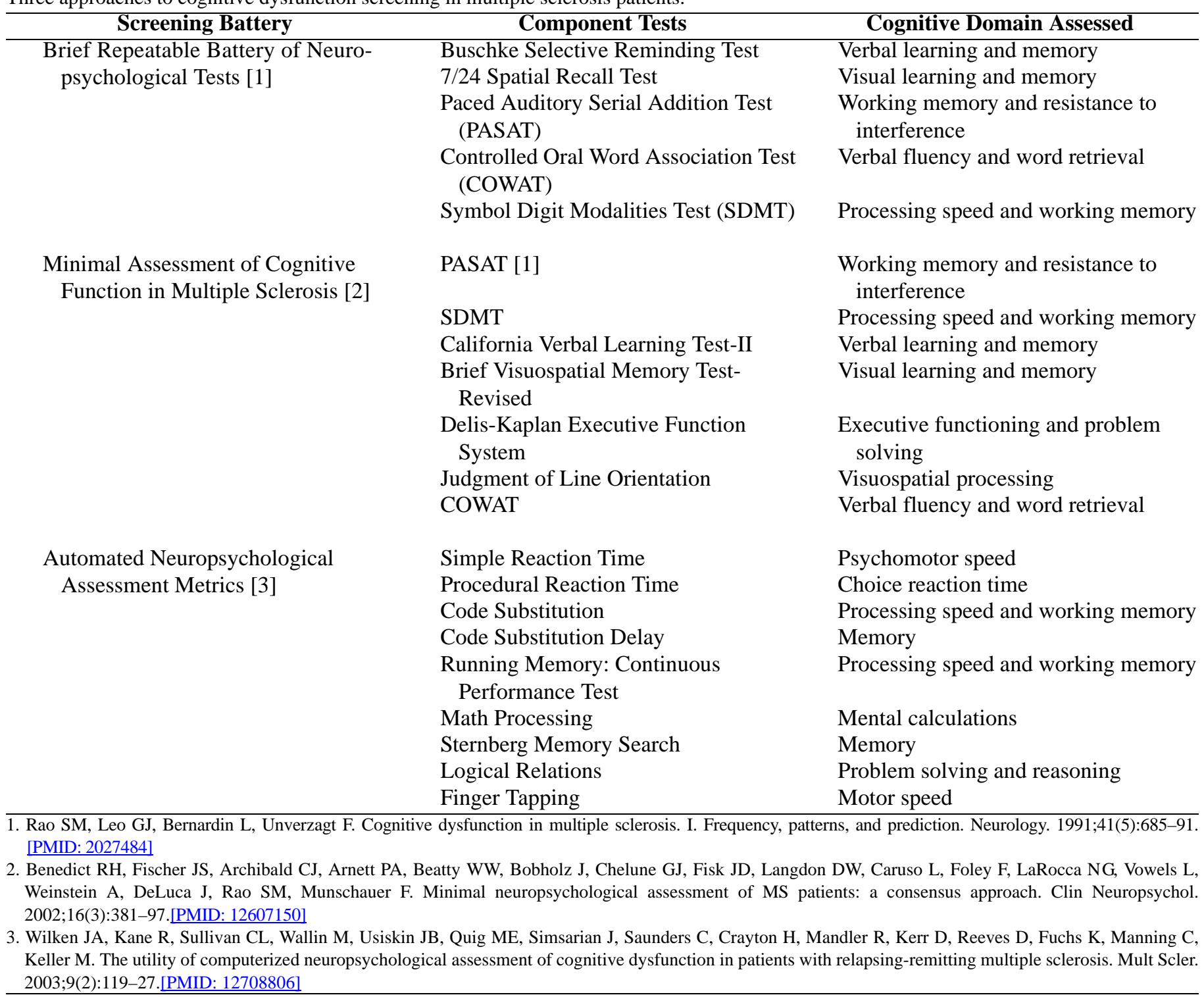

appears to be low. Thus, the BRB-N may not be useful for monitoring therapeutic efficacy in clinical trials [19].

A committee sponsored by the Consortium of MS Centers proposed a somewhat longer battery that was time-efficient and comprehensive in its coverage of deficits commonly seen in MS [20]. The Minimal Assessment of Cognitive Function in MS (MACFIMS) was compiled for neuropsychologists to use as a battery; it contains the minimal number of measures necessary for the comprehensive assessment of MS patients. Thus, nonneuropsychologists cannot use it in a general neurology practice. The battery covers major MS cognitive deficits, including processing speed, working memory, learning and memory, executive functioning, visuospatial processing, and word retrieval. The recommended measures for the MACFIMS battery are listed in Table 1.

The MACFIMS can be administered in approximately 90 minutes. Although adequate sensitivity and specificity were reported in the original article about the MACFIMS, little research using this battery has been published. Thus, no data exist regarding its usefulness in assessing medication efficacy.

An alternate approach that uses a brief, repeatable computerized battery has been piloted as an initial screening 
battery for patients with MS [21]. This computerized screening battery uses the Automated Neuropsychological Assessment Metrics (ANAM) battery that was developed by the Department of Defense and is currently available to the Department of Veterans Affairs (VA) and other research institutions. The impetus behind this approach was the development of a brief, economical method of screening MS patients with cognitive changes. Patients who show potential cognitive changes during screening can be referred for a more comprehensive neuropsychological examination. Patients not showing cognitive changes would not be tested further.

The brief computerized MS battery was derived from the larger ANAM test system [22-23]. The ANAM test system is composed of approximately 40 tests that assess mood and various aspects of cognitive and motor functioning. The brief computerized battery has been used with MS patients [21] and is similar in length to the BRB-N developed by Rao et al. [1]. Current data support the sensitivity of this brief, automated screening procedure with MS, and investigations of the methodology continue.

Because the ANAM is automated, a patient can complete testing with only the assistance of a test administrator. The training of test administrators will vary depending upon whether they work in a Federal or nonFederal institution and the applicable licensing laws in a given state. The results, however, still require interpretation by a neuropsychologist. Thus, the ANAM could be used in a neurology office for triage. In addition, the ANAM has many alternate forms and can be used for following changes throughout the course of the disease and in response to medication. The ANAM's response-time precision makes it ideal for detecting the subtle changes in information processing speed that are often observed in MS patients. This feature is also helpful for accurately tracking temporal trends or effects of treatment on cognitive status.

Preliminary research with the ANAM indicates that it correctly categorizes MS patients as cognitively intact or impaired. Specifically, a logistic regression indicated that the ANAM accurately predicted the performance of 48 patients as intact or impaired 96 percent of the time [21]. Presently, follow-up studies are being conducted for further validation of ANAM use with MS patients. Of note, an Internet-enabled version of the ANAM will be used in a telemedicine initiative of the VA MS Center of Excellence (MSCoE) East, Baltimore, Maryland.

\section{IMAGING CHARACTERISTICS}

Biomarkers of a disease are characteristics that are objectively measured and are indicators of normal biological processes, pathological processes, or pharmacological responses [24]. Neuroimaging is the most well studied biomarker of cognitive dysfunction in MS. Modern imaging techniques provide a clearer picture of damage to myelin and neurons within the central nervous system (CNS), which is the major cause of cognitive dysfunction. Demyelination and axonal transection in white matter lesions are evident on traditional magnetic resonance imaging (MRI) scans. In addition, newer imaging procedures can also differentiate structural damage to neurons in normal-appearing white and gray matter (via MRI spectroscopy and diffusion-weighted MRI) and can map real-time CNS activation during neuropsychological testing (via functional MRI).

Standard MRI provided the earliest evidence that the extent of cerebral involvement is the key predictor of cognitive dysfunction in MS. Overall $\mathrm{T}^{*}{ }^{*}$ lesion area [25], $\mathrm{T}^{\dagger}$ and T2 lesion load [26-27], and number of juxtacortical lesions [28] predict deterioration across a number of cognitive domains. Given that cerebral atrophy is increasingly associated with worsening MS, volumetric analysis has also been the focus of much recent research on cognition. Studies looking at total brain parenchymal volume have indicated that global atrophy is strongly correlated with development of cognitive dysfunction in MS [29-30]. When the association between volume and size of individual structures (e.g., ventricle width, bicaudate ratio) and cognitive dysfunction was examined, central atrophy as measured by the third ventricle width more strongly predicted cognitive dysfunction than either global atrophy or lesion load [31]. Such data have led many in the field to consider that brain volume more accurately predicts cognitive dysfunction than traditional lesion burden.

Newer brain imaging techniques such as magnetization transfer, diffusion tensor imaging, and functional MRI have enabled researchers to examine brain regions that appear normal on traditional MRI scans. For example, Audoin et al. showed that compared with controls, early relapsing-remitting MS patients had greater activation in

\footnotetext{
* Characteristic decay time caused by dephasing of coherent procession of nuclei following radio frequency pulse.

${ }^{\dagger}$ Longitudinal relaxation time that reflects time taken for nuclei to return to thermal equilibrium.
} 
the right frontal cortex, bilateral prefrontal cortex, and right cerebellum when performing an attention task [32]. These changes imply that MS patients use compensatory cortical activations early in their disease course. Diffusion tensor MRI techniques have found moderate correlations among normal-appearing brain tissue, both white and gray matter, and cognitive testing [33]. MRI spectroscopy can been used for quantitation of neuronal loss by measurement of $\mathrm{N}$-acetyl aspartate levels in a desired brain region. Pan et al. found significant correlations between high periventricular $\mathrm{N}$-acetyl aspartate levels and impaired performance on cognitive testing [34]. In sum, mounting evidence indicates that damage to white and gray matter structures within the CNS is significantly correlated with cognitive dysfunction in MS [29-35]. Continued study and improved imaging techniques may better elucidate the pathology of cognitive dysfunction in MS and the compensatory mechanisms that MS patients with cognitive dysfunction use.

\section{RISK FACTORS}

Cross-sectional, retrospective, and prospective study designs can be used for evaluating risk factors. Traditionally, a risk factor is defined as a demographic characteristic, environmental exposure, event, or genetic factor that influences the probability of developing a given condition. It is a broad term that includes biomarkers or any potential etiologic agent under study that may influence a disease. Unfortunately, few studies have evaluated risk factors for the development of cognitive dysfunction in MS. The majority of recent studies have been cross-sectional or retrospective [1,35-42] and the remainder longitudinal [5,43-47].

Table 2 lists some recently reported risk factors for cognitive dysfunction in MS. These variables should be considered candidate risk factors because many have only been confirmed by a single study. For example, the course

Table 2.

Risk factors for cognitive dysfunction in multiple sclerosis (MS) based on selected recent reports.

\begin{tabular}{|c|c|}
\hline ctor & \\
\hline Length of Disease & for \\
\hline Race & \\
\hline CS & O1 \\
\hline MS & Incr \\
\hline lity & SC \\
\hline Mild Cognitive & Inc \\
\hline \multicolumn{2}{|r|}{ tive dysfunction in early-onset multiple sclerosis: a reappraisal after 10 years. Arch Neurol. 2001;58(10):1602-6. } \\
\hline \multicolumn{2}{|c|}{$\begin{array}{l}\text { 2. McIntosh-Michaelis SA, Roberts MH, Wilkinson SM, Diamond ID, McLellan DL, Martin JP, Spackman AJ. The prevalence of cognitive impairment in a com- } \\
\text { munity survey of multiple sclerosis. Br J Clin Psychol. 1991;30(Pt 4):333-48. [PMID: 1777755] }\end{array}$} \\
\hline \multicolumn{2}{|c|}{$\begin{array}{l}\text { 3. Piras MR, Magnano I, Canu ED, Paulus KS, Satta WM, Soddu A, Conti M, Achene A, Solinas G, Aiello I. Longitudinal study of cognitive dysfunction in mul- } \\
\text { tiple sclerosis: neuropsychological, neuroradiological, and neurophysiological findings. J Neurol Neurosurg Psychiatry. 2003;74(7):878-85. [PMID: 12810771] }\end{array}$} \\
\hline \multicolumn{2}{|c|}{$\begin{array}{l}\text { 5. Oliveri RL, Cittadella R, Sibilia G, Manna I, Valentino P, Gambardella A, Aguglia U, Zappia M, Romeo N, Andreoli V, Bono F, Caracciolo M, Quattrone A. } \\
\text { APOE and risk of cognitive impairment in multiple sclerosis. Acta Neurol Scand. 1999;100(5):290-95. [PMID: 10536914] }\end{array}$} \\
\hline \multicolumn{2}{|c|}{ 6. Thornton AE, Raz N. Memory impairment in multiple sclerosis: a quantitative review. Neuropsychology. 1997;11(3):357-66. [PMID: 9223140] } \\
\hline \multicolumn{2}{|c|}{$\begin{array}{l}\text { 7. Feinstein A, Kartsounis LD, Miller DH, Youl BD, Ron MA. Clinically isolated lesions of the type seen in multiple sclerosis: a cognitive, psychiatric, and MRI } \\
\text { follow-up study. J Neurol Neurosurg Psychiatry. 1992;55(10):869-76. [PMID: 1431949] }\end{array}$} \\
\hline \multicolumn{2}{|c|}{$\begin{array}{l}\text { 8. Camp SJ, Stevenson VL, Thompson AJ, Miller DH, Borras C, Auriacombe S, Brochet B, Falautano M, Filippi M, Herisse-Dulo L, Montalban X, Parrcira E, } \\
\text { Polman CH, De Sa J, Langdon DW. Cognitive function in primary progressive and transitional progressive multiple sclerosis: a controlled study with MRI cor- } \\
\text { relates. Brain. 1999;122(Pt 7):1341-48. [PMID: 10388799] }\end{array}$} \\
\hline \multicolumn{2}{|c|}{$\begin{array}{l}\text { 9. Comi G, Filippi M, Martinelli V, Campi A, Rodegher M, Alberoni M, Sirabian G, Canal N. Brain MRI correlates of cognitive impairment in primary and sec- } \\
\text { ondary progressive multiple sclerosis. J Neurol Sci. 1995;132(2):222-27.[PMID: 8543952] }\end{array}$} \\
\hline & \\
\hline
\end{tabular}


of MS seems to influence the degree of cognitive dysfunction. In a number of studies, cognitive dysfunction was found to be more severe in secondary progressive MS patients than relapsing-remitting MS patients [38-39,47]. Primary progressive MS is somewhat unique because, despite disability levels similar to secondary progressive MS, patients' cognitive function is often preserved [38]. This finding is not unexpected because primary progressive MS largely involves spinal cord pathology.

Otherwise healthy individuals with mild cognitive dysfunction have been shown to be at risk for more rapid cognitive decline and more frequent development of incident Alzheimer's dementia than individuals with no cognitive dysfunction [48]. Similarly, Kujala et al. found that MS patients with mild cognitive dysfunction at baseline showed rapid declines in cognitive function on neuropsychological testing over a 3 year period compared with MS patients with intact cognitive function at baseline who remained cognitively stable over the testing period [45].

Some studies have produced inconsistent results when clinical variables were examined as risk factors for MS cognitive dysfunction. For example, increasing length of disease was correlated with worsening cognitive dysfunction in several studies $[5,40,46]$ but not others [1]. Similarly, physical disability and MS cognitive dysfunction were not significantly correlated in some reports $[1,46]$ but significantly correlated in others [5]. A recent longitudinal study of MS patients found that physical symptoms in MS patients progressed at different rates than cognitive dysfunction $[5,49]$. These results seemingly indicate a dissociation between cognitive dysfunction and MS disability as measured by the Expanded Disability Status Scale (EDSS) [50]. Some of these disparities are the result of patient populations with differing baseline disability levels and variable follow-up periods.

Racial and genetic characteristics may influence the development of cognitive dysfunction in MS. African Americans with MS were evaluated by the New York State MS Consortium in a longitudinal study of more than 5,600 patients [43]. African Americans were 6 percent of this study cohort and more likely to have higher EDSS scores with increased disease duration. Cognitive dysfunction, as measured by the EDSS cerebral functional system score, developed earlier in the course of MS in African Americans compared with non-African Americans. The functional system score is, unfortunately, an insensitive measure of cognition; formal neuropsychological tests would have provided a more comprehensive picture of the temporal trends. Still, this report indicates that African Americans with MS may be at increased risk for an aggressive disease course.

Oliveri et al. studied whether the apolipoprotein E (APOE) gene polymorphism and the regulatory region of the $-491 \mathrm{~A} / \mathrm{T}$ (adenine/thymine) polymorphism are risk factors for cognitive dysfunction in MS [36]. This gene and various associated alleles have been shown to increase the risk of Alzheimer's disease. While the APOE polymorphism did not significantly predict cognitive dysfunction in MS patients, the AA (homozygous dominant) combination of the $-491 \mathrm{~A} / \mathrm{T}$ polymorphism was associated with cognitive dysfunction.

Finally, Honig et al. demonstrated that visual evoked potentials may be useful markers of cognitive dysfunction in MS patients [41]. They examined the P300 event-related potential in 32 MS patients with cognitive dysfunction. The P300 latency was strongly correlated with cognitive dysfunction but weakly correlated with MS disability as measured by the EDSS. Piras et al. found similar results [46]. Other investigators have found abnormalities in auditory evoked potentials that correlate with cognitive dysfunction in MS patients [42]. Evoked potentials depend on intact cerebral white matter connections, and abnormalities in latency and wave form may help predict or track cognitive dysfunction in MS patients. Larger longitudinal studies are needed for determining whether evoked potential components can be used as predictors of future cognitive dysfunction in MS patients.

\section{CONCLUSIONS}

Studies in recent years have clarified the pattern of cognitive dysfunction in MS. A dissociation often exists between cognitive dysfunction in MS and traditional neurological deficits. With increasing numbers of imaging and clinical assessment tools, researchers have started to identify risk factors and biological markers of cognitive dysfunction in MS. Correlations between cognitive dysfunction and neuroimaging parameters, however, remain moderate at best. Newer imaging techniques such as diffusion tensor MRI, functional MRI, and MRI spectroscopy will hopefully better clarify structural-functional relationships. Additionally, because cognitive dysfunction assessment in MS has traditionally been time consuming, efforts should be made toward integrating shorter assessment batteries such as the ANAM into routine clinical 
examinations. The VA MSCoE East has initiated projects to make these assessments practical and efficient for patients and healthcare providers.

Finding and confirming risk factors for cognitive dysfunction will be challenging because MS is a complex, dynamic disease that evolves slowly. Longitudinal MS studies that assess biological markers and temporal trends in cognitive dysfunction are particularly needed. With the recent advances in molecular neuroscience that have contributed to advances in other dementia disorders [51], we remain optimistic about the future. The goal of research efforts is early identification of MS patients who will develop cognitive dysfunction. Ultimately, these patients would receive therapy that would modify the disease course in the presymptomatic period.

\section{ACKNOWLEDGMENT}

This material is the result of work supported with resources and the use of facilities at the VA MSCoE, Baltimore, Maryland.

\section{REFERENCES}

1. Rao SM, Leo GJ, Bernardin L, Unverzagt F. Cognitive dysfunction in multiple sclerosis. I. Frequency, patterns, and prediction. Neurology. 1991;41(5):685-91. [PMID: 2027484]

2. Turner MA, Moran NF, Kopelman MD. Subcortical dementia. Br J Psychiatry. 2002;180:148-51. [PMID: 11823326]

3. Rao SM, Leo GJ, Ellington L, Nauertz T, Bernardin L, Unverzagt F. Cognitive dysfunction in multiple sclerosis. II. Impact on employment and social functioning. Neurology. 1991;41(5):692-96. [PMID: 1823781]

4. Wishart H, Sharpe D. Neuropsychological aspects of multiple sclerosis: a quantitative review. J Clin Exp Neuropsychol. 1997;19(6):810-24. [PMID: 9524876]

5. Amato MP, Ponziani G, Siracusa G, Sorbi S. Cognitive dysfunction in early-onset multiple sclerosis: a reappraisal after 10 years. Arch Neurol. 2001;58(10):1602-6. [PMID: 11594918]

6. Wilken JA, Wallin MT, Sullivan CL, Usiskin JB, Kane RL, Simsarian J, Saunders C, Mikszewski J, Rossman H, Lawson S, Kerr D, Crayton H, Quig ME. Combination therapy (Provigil + Avonex) in the treatment of attention problems in patients with relapsing-remitting MS [abstract]. Neurology. 2004;64(Suppl 1):P05.141.

7. Fischer JS, Priore RL, Jacobs LD, Cookfair DL, Rudick RA, Herndon RM, Richert JR, Salazar AM, Goodkin DE,
Granger CV, Simon JH, Grafman JH, Lezak MD, O’Reilly Hovey KM, Perkins KK, Barilla-Clark D, Schacter M, Shucard DW, Davidson AL, Wende KE, Bourdette DN, Kooijmans-Coutinho MF. Neuropsychological effects of interferon $\beta$-1a in relapsing multiple sclerosis. Multiple Sclerosis Collaborative Research Group. Ann Neurol. 2000;48(6):885-92. [PMID: 11117545]

8. Geisler MW, Sliwinski M, Coyle PK, Masur DM, Doscher C, Krupp LB. The effects of amantadine and pemoline on cognitive functioning in multiple sclerosis. Arch Neurol. 1996;53(2):185-88. [PMID: 8639070]

9. Greene YM, Tariot PN, Wishart H, Cox C, Holt CJ, Schwid S, Noviasky J. A 12-week, open trial of donepezil hydrochloride in patients with multiple sclerosis and associated cognitive impairments. J Clin Psychopharmacol. 2000;20(3): 350-56. [PMID: 10831023]

10. Fischer JS. Cognitive impairment in multiple sclerosis. In: Cook SD, editor. Handbook of multiple sclerosis. 3rd ed. New York (NY): Marcel Dekker, Inc; 2001. p. 233-56.

11. Heaton RK, Nelson LM, Thompson DS, Burks JS, Franklin GM. Neuropsychological findings in relapsing-remitting and chronic-progressive multiple sclerosis. J Consult Clin Psychol. 1985;53(1):103-10. [PMID: 3980815]

12. Arnett PA, Higginson CI, Voss WD, Randolph JJ, Grandey AA. Relationship between coping, cognitive dysfunction and depression in multiple sclerosis. Clin Neuropsychol. 2002;16(3):341-55. [PMID: 12607147]

13. Romani A, Bergamaschi R, Candeloro E, Alfonsi E, Callieco R, Cosi V. Fatigue in multiple sclerosis: multidimensional assessment and response to symptomatic treatment. Mult Scler. 2004;10(4):462-68. [PMID: 15327047]

14. Tartaglia MC, Narayanan S, Francis SJ, Santos AC, De Stefano N, Lapierre Y, Arnold DL. The relationship between diffuse axonal damage and fatigue in multiple sclerosis. Arch Neurol. 2004;61(2):201-7. [PMID: 14967766]

15. Richter P, Werner J, Heerlein A, Kraus A, Sauer H. On the validity of the Beck Depression Inventory. A review. Psychopathology. 1998;31(3):160-68. [PMID: 9636945]

16. Krupp LB, LaRocca NG, Muir-Nash J, Steinberg AD. The fatigue severity scale. Application to patients with multiple sclerosis and systemic lupus erythematosus. Arch Neurol. 1989;46(10):1121-23. [PMID: 2803071]

17. Cummings JL, Benson DF. Dementia: a clinical approach. Boston (MA): Butterworth; 1983.

18. Zarei M, Chandran S, Compston A, Hodges J. Cognitive presentation of multiple sclerosis: evidence for a cortical variant. J Neurol Neurosurg Psychiatry. 2003;74(7):872-77. [PMID: 12810770]

19. Rao SM. Cognitive function in patients with multiple sclerosis: impairment and treatment. Int J MS Care. 2004;4(1): 9-22. 
20. Benedict RH, Fischer JS, Archibald CJ, Arnett PA, Beatty WW, Bobholz J, Chelune GJ, Fisk JD, Langdon DW, Caruso L, Foley F, LaRocca NG, Vowels L, Weinstein A, DeLuca J, Rao SM, Munschauer F. Minimal neuropsychological assessment of MS patients: a consensus approach. Clin Neuropsychol. 2002;16(3):381-97. [PMID: 12607150]

21. Wilken JA, Kane RL, Sullivan CL, Wallin MT, Usiskin JB, Quig ME, Simsarian J, Saunders C, Crayton H, Mandler R, Kerr D, Reeves DL, Fuchs K, Manning C, Keller M. The utility of computerized neuropsychological assessment of cognitive dysfunction in patients with relapsing-remitting multiple sclerosis. Mult Scler. 2003;9(2):119-27. [PMID: 12708806]

22. Reeves DL, Winter K, LaCour S, Raynsford K, Kay G, Elsmore T, Hegge FW. Automated neuropsychological assessment metrics documentation. Vol I. Test administration guide. Washington (DC): Office of Military Performance Assessment Technology; 1992.

23. Kane RL, Reeves DL. Computerized test batteries. In: Horton A, Wedding D, Webster J, editors. The neuropsychology handbook. New York (NY): Springer; 1997.

24. Bielekova B, Martin R. Development of biomarkers in multiple sclerosis. Brain. 2004;127(Pt 7):1463-78. [PMID: 15180926]

25. Rao SM, Leo GJ, Haughton VM, St Aubin-Faubert P, Bernardin L. Correlation of magnetic resonance imaging with neuropsychological testing in multiple sclerosis. Neurology. 1989;39(2 Pt 1):161-66. [PMID: 2915783]

26. Comi G, Rovaris M, Falautano M, Santuccio G, Martinelli V, Rocca MA, Possa F, Leocani L, Paulesu E, Filippi M. A multiparametric MRI study of frontal lobe dementia in multiple sclerosis. J Neurol Sci. 1999;171(2):135-44. [PMID: 10581380]

27. Rovaris M, Filippi M, Falautano M, Minicucci L, Rocca MA, Martinelli V, Comi G. Relation between MR abnormalities and patterns of cognitive impairment in multiple sclerosis. Neurology. 1998;50(6):1601-8. [PMID: 9633700]

28. Lazeron RH, Langdon DW, Filippi M, Van Waesberghe $\mathrm{JH}$, Stevenson VL, Boringa JB, Origgi D, Thompson AJ, Falautano M, Polman CH, Barkhof F. Neuropsychological impairment in multiple sclerosis patients: the role of (juxta)cortical lesion on FLAIR. Mult Scler. 2000;6(4): 280-85. [PMID: 10962549]

29. Zivadinov R, De Masi R, Nasuelli D, Bragadin LM, Ukmar M, Pozzi-Mucelli RS, Grop A, Cazzato G, Zorzon M. MRI techniques and cognitive impairment in the early phase of relapsing-remitting multiple sclerosis. Neuroradiology. 2001;43(4):272-78. [PMID: 11338408]

30. Zivadinov R, Sepcic J, Nasuelli D, De Masi R, Bragadin LM, Tommasi MA, Zambito-Marsala S, Moretti R, Bratina A, Ukmar M, Pozzi-Mucelli RS, Grop A, Cazzato G, Zorzon M. A longitudinal study of brain atrophy and cognitive disturbances in the early phase of relapsing-remitting multiple sclerosis. J Neurol Neurosurg Psychiatry. 2001;70(6): 773-80. [PMID: 11385012]

31. Benedict RH, Carone DA, Bakshi R. Correlating brain atrophy with cognitive dysfunction, mood disturbances, and personality disorder in multiple sclerosis. J Neuroimaging. 2004;14(3 Suppl):S36-45. [PMID: 15228758]

32. Audoin B, Ibarrola D, Ranjeva JP, Confort-Gouny S, Malikova I, Ali-Cherif A, Pelletier J, Cozzone P. Compensatory cortical activation observed by fMRI during a cognitive task at the earliest stage of MS. Hum Brain Mapp. 2003;20(2):51-58. [PMID: 14505331]

33. Rovaris M, Iannucci G, Falautano M, Possa F, Martinelli V, Comi G, Filippi M. Cognitive dysfunction in patients with mildly disabling relapsing-remitting multiple sclerosis: an exploratory study with diffusion tensor MR imaging. J Neurol Sci. 2002;195(2):103-9. [PMID: 11897239]

34. Pan JW, Krupp LB, Elkins LE, Coyle PK. Cognitive dysfunction lateralizes with NAA in multiple sclerosis. Appl Neuropsychol. 2001;8(3):155-60. [PMID: 11686650]

35. Camp SJ, Stevenson VL, Thompson AJ, Miller DH, Borras C, Auriacombe S, Brochet B, Falautano M, Filippi M, Herisse-Dulo L, Montalban X, Parrcira E, Polman CH, De Sa J, Langdon DW. Cognitive function in primary progressive and transitional progressive multiple sclerosis: a controlled study with MRI correlates. Brain. 1999;122(Pt 7):1341-48. [PMID: 10388799]

36. Oliveri RL, Cittadella R, Sibilia G, Manna I, Valentino P, Gambardella A, Aguglia U, Zappia M, Romeo N, Andreoli V, Bono F, Caracciolo M, Quattrone A. APOE and risk of cognitive impairment in multiple sclerosis. Acta Neurol Scand. 1999;100(5):290-95. [PMID: 10536914]

37. Thornton AE, Raz N. Memory impairment in multiple sclerosis: a quantitative review. Neuropsychology. 1997;11(3): 357-66. [PMID: 9223140]

38. Comi G, Filippi M, Martinelli V, Campi A, Rodegher M, Alberoni M, Sirabian G, Canal N. Brain MRI correlates of cognitive impairment in primary and secondary progressive multiple sclerosis. J Neurol Sci. 1995;132(2):222-27. [PMID: 8543952]

39. Beatty WW, Goodkin DE, Monson N, Beatty PA. Cognitive disturbances in patients with relapsing-remitting multiple sclerosis. Arch Neurol. 1989;46(10):1113-19. [PMID: 2803070]

40. McIntosh-Michaelis SA, Roberts MH, Wilkinson SM, Diamond ID, McLellan DL, Martin JP, Spackman AJ. The prevalence of cognitive impairment in a community survey of multiple sclerosis. Br J Clin Psychol. 1991;30(Pt 4): 333-48. [PMID: 1777755

41. Honig LS, Ramsay RE, Sheremata WA. Event-related potential P300 in multiple sclerosis. Relation to magnetic 
resonance imaging and cognitive impairment. Arch Neurol. 1992;49(1):44-50. [PMID: 1728263]

42. Newton MR, Barrett G, Callanan MM, Towell AD. Cognitive event-related potentials in multiple sclerosis. Brain. 1989;112(Pt 6):1637-60. [PMID: 2598002]

43. Weinstock-Guttman B, Jacobs LD, Brownscheidle CM, Baier M, Rea DF, Apatoff BR, Blitz KM, Coyle PK, Frontera AT, Goodman AD, Gottesman MH, Herbert J, Holub R, Lava NS, Lenihan M, Lusins J, Mihai C, Miller AE, Perel AB, Snyder DH, Bakshi R, Granger CV, Greenberg SJ, Jubelt B, Krupp L, Munschauer FE, Rubin D, Schwid S, Smiroldo J, New York State Multiple Sclerosis Consortium. Multiple sclerosis characteristics in African American patients in the New York State Multiple Sclerosis Consortium. Mult Scler. 2003;9(3):293-98. [PMID: 12814178]

44. Feinstein A, Kartsounis LD, Miller DH, Youl BD, Ron MA. Clinically isolated lesions of the type seen in multiple sclerosis: a cognitive, psychiatric, and MRI follow-up study. J Neurol Neurosurg Psychiatry. 1992;55(10):869-76. [PMID: 1431949]

45. Kujala P, Portin R, Ruutiainen J. The progress of cognitive decline in multiple sclerosis. A controlled 3-year followup. Brain. 1997;120(Pt 2):289-97. [PMID: 9117376]

46. Piras MR, Magnano I, Canu ED, Paulus KS, Satta WM, Soddu A, Conti M, Achene A, Solinas G, Aiello I. Longitudinal study of cognitive dysfunction in multiple sclerosis: neuropsychological, neuroradiological, and neurophysiological findings. J Neurol Neurosurg Psychiatry. 2003;74(7): 878-85. [PMID: 12810771]

47. Hohol MJ, Guttmann CR, Orav J, Mackin GA, Kikinis R, Khoury SJ, Jolesz FA, Weiner HL. Serial neuropsychological assessment and magnetic resonance imaging analysis in multiple sclerosis. Arch Neurol. 1997;54(8):1018-25.

[PMID: 9267977]

48. Bennett DA, Wilson RS, Schneider JA, Evans DA, Beckett LA, Aggarwal NT, Barnes LL, Fox JH, Bach J. Natural history of mild cognitive impairment in older persons. Neurology. 2002;59(2):198-205. [PMID: 12136057]

49. Amato MP, Ponziani G, Pracucci G, Bracco L, Siracusa G, Amaducci L. Cognitive impairment in early-onset multiple sclerosis. Pattern, predictors, and impact on everyday life in a 4-year follow-up. Arch Neurol. 1995;52(2):168-72. [PMID: 7848126]

50. Kurtzke JF. Rating neurologic impairment in multiple sclerosis: an Expanded Disability Status Scale (EDSS). Neurology. 1983;33(11):1444-52. [PMID: 6685237]

51. Morris JC. Dementia update 2003. Alzheimer Dis Assoc Disord. 2003;17(4):245-58. [PMID: 14657790]

Submitted for publication September 13, 2004. Accepted in revised form January 5, 2005. 